\title{
Study profile of patients of Bundelkhand region Presenting with low vision
}

\author{
Dr. Jitendra kumar ${ }^{1}$, Dr. Shweta dwivedi ${ }^{2}$, Dr Amit Verma ${ }^{3}$, \\ Dr.Arun kumar Pathak \\ ${ }^{1,2,3,4}$ (Department of Ophthalmology,M.L.B.Medica lCollege/Bundelkhand University,India)
}

\begin{abstract}
Background: Low vision is an important public health problem. The purpose of this study was to describe the characteristics of patients attending the medical college, Jhansi(U.P).

Methods: This was a prospective cross sectional study of all new patients seen at the Ophthalmology department, Medical College, Jhansi over a 12 month period. Patients were administered with a structured questionnaire, and were examined and tested with low vision devices by the attending low vision specialist. Information on the demographic and clinical characteristics of the patients was recorded.

Results: A total of 150 new patients seen during the period were studied. The mean age was 37.5 years, and their ages ranged between 5 and 80 years with a male to female ratio of 2:1.Patients in the age group of 5-30 yrs were $23.3 \%$, in $26-55$ yrs were $35.3 \%$ and in $56-80$ yrs were $41.3 \%$. The commonest cause of low vision was $\operatorname{ARMD}(24 \%) ; 20 \%$ had Corneal opacity ; $18 \%$ had Optic atrophy; while only $2 \%$ had Non specific maculopathy, macular scars, and macular hole. ARMD ( 17.33\%) was the commonest cause in the elderly patients, while amblyopia(6.66\%) the commonest in children.

Conclusion: The demographic and clinical characteristics of low vision patients seen are similar to that of patients in other developing countries, but different from those in developed countries. Elderly patients and females may be under-utilizing low vision services. There is a need for further research into the determinants of low vision service utilization in developing countries. This would further aid the planning and delivery of services to low vision patients in these countries.
\end{abstract}

Keywords: Low vision, Patient characteristics, Developing countries

\section{Introduction}

Low vision is a condition caused by eye disease, in which visual acuity is 20/70 or poorer in the betterseeing eye and cannot be corrected or improved with regular eyeglasses. (Scheiman, Scheiman and Whittaker). A person with low vision is one who has impaired visualfunction despite treatment of eye disease and/ or correction of refractive error, and has reduced visual acuity in the better eye which is less than $6 / 18$ but better than light perception(LP) or a visual field constriction to less than $10^{\circ}$, but who uses or is potentially able to use vision for the planning and/ or execution of a task [1]. This definition of low vision excludes individuals whose visual acuity could be improved by surgical and/or medical treatment and refers to functional vision. The term "functional low vision" has been used to represent this definition in a bid to the avoid confusion with other definitions[2-4].

People with functional low vision require assessment for low vision interventions [2], and such patients are the focus of this article .Functionally, low vision is characterized by irreversible visual loss and a reduced ability to perform many daily activities, such as recognising people in the street, reading blackboards, writing at the same speed as peers, and playing with friends [5]. It is an important public health problem [6]; and provision of low vision services is one of the priorities in the global initiative, VISION 2020-The Right to Sight [2,7].It is important to collect and analyse clinical data from patients with functional low vision in order to deliver appropriate low vision care. This study is carried out to describe the demographic and clinical characteristics of patients presenting with low vision in our hospital. We believe that the information about patients who actually present to us with low vision clinics would be useful for planning and delivery of effective low vision services.

\section{Method}

This was a prospective cross sectional study of all new patients seen at ophthalmology department, M.L.B.Medical College, Jhansi(U.P) between January 2015 and December 2015. 
Study population Clients who attend the low vision clinic comprise of patients who have been treated at the main eye clinic for various ailments but whose vision needs were not adequately met by conventional methods [1]. Thus, most subjects with operable cataracts were not included in this study. All patients presenting with low vision are seen by an ophthalmologist .All the patients seen during the study period were administered with a structured questionnaire, and were examined and tested with different low vision devices by the attending ophthalmologist. Information on the demographic and clinical characteristics of the patients was recorded. Visual acuity (VA) was assessed with the use of Early Treatment Diabetic Retinopathy Study(ETDRS) charts and recorded in logarithm of the minimum angle of resolution (logMAR) units for distance vision and metric units (M) for near vision. Distance visual acuity of counting fingers, hand motion, light perception(LP) and nil light perception (NLP) were assigned $\log$ MAR values of 1.9, 2.3, 2.7 and 3.0 respectively[8-10]. Colour vision was tested by Ishihara's chart.

\section{Results}

A total of 150 new patients presented and were seen at the ophthalmology department during the study period. The mean age was (37.5 ) years. Their ages ranged between 5 and 80 years. Majority $(66.6 \%)$ of the patients were males with a male to female ratio of $2: 1$. The age distribution of the patients is shown in Table 1.Thirty five (23.3\%) patients were children ( $5-80$ years), 53 (35.3\%) were aged between 26 -55 years, while 62 $(41.3 \%)$ of them were elderly patients (56-80 years). The mean age of the male patients was 41.3 years while that of females was 35.7 years $[\mathrm{t}=1.84 ; \mathrm{p}=0.067]$.

Table 1: Age distribution of low vision patients

\begin{tabular}{|c|c|c|}
\hline Age group (years) & Frequency (n) & Percent (\%) \\
\hline $\begin{array}{l}5-30 \\
26-55 \\
56-80\end{array}$ & $\begin{array}{ll}35 & \\
& 53 \\
& 62\end{array}$ & $\begin{array}{l}23.3 \\
35.3 \\
41.3\end{array}$ \\
\hline Total & 150 & 100 \\
\hline
\end{tabular}

With regards to the main presenting complaint, 103(53.4\%) patients complained of both poor distance and near vision indicating that both distance and near vision were of equal importance to them. Thirty nine (20.2\%) patients said their major problem was with distance vision, while 38 (19.7\%) reported that their main complaint was poor near vision. $30(20 \%)$ patient was mainly concerned about restriction of his visual field .Amongst the patients with poor distance vision as their main problem, $41.0 \%$ were children and $7.7 \%$ were elderly patients; but among those with poor near vision as their major complaint, only $13.2 \%$ were children while $36.8 \%$ were elderly patients $[\chi 2=12.89 ; \mathrm{p}=0.002]$. The median presenting distance VA in the better eye was 1.20 $\log$ MAR with an interquartile range (IQR) of $0.90-1.36 \log$ MAR. The median distance VA of the right eyes was $1.30 \operatorname{logMAR}(\mathrm{IQR}$ : $1.00-1.52$ ); the median for the left eyes was also $1.30 \log$ MAR (IQR: $0.97-$ 1.50). The right eye had the better VA in $60(31.1 \%)$ patients, the left eye was better in $54(28 \%)$ patients, while the visual acuity was equal in both eyes of 79 (40.9\%) patients. The median near visual acuity was 2.5 Metric units (IQR:1.25 - 5.00). The median near VA among patients aged40 years and above was 4.0 Metric units (IQR: $1.60-6.30$ ); while in those aged below 40 years it was 2.0 Metric units(IQR: $1.00-3.20$ ). Colour vision was normal in $120(80 \%)$ patients, while 30 (20\%) patients had nystagmus. The commonest cause of low vision was ARMD in 36(24\%) patients. The causes of low vision are presented in Table 2.

Table 2: Causes of low vision

\begin{tabular}{|l|l|l|}
\hline Cause of low vision & Frequency (n) & Percent (\%) \\
\hline ARMD & 36 & \\
Comeal opacity & 30 & 24 \\
Optic atrophy & 27 & 20 \\
Glaucoma & 27 & 18 \\
Amblyopia & 12 & 18 \\
Degenerative myopia & 9 & 8 \\
Non-specific & 3 & 6 \\
maculopathy & 3 & 2 \\
Bilateralmacular scars & 3 & 2 \\
Macular hole & & 2 \\
\hline Total & 150 & 100.0 \\
\hline
\end{tabular}


In majority $(80 \%)$ of the patientsthe cause of low vision involved posterior segment disease.The commonest causes of low vision among 5-30 year age group were amblyopia and degenerative myopia, each accounting for $\%$ and $6 \%$ respectively. Among the adults aged 31-55 years, the commonestcauses wereglaucoma and corneal opacities occurring in $10 \%$ eachof patients. While in the elderly (56-80 years),ARMD (17.33\%) was the commonest. The relative frequency of the three differentage groups within each of the major causes of low vision is presented in Figure 1.

Fig 1 : Frequency Of Diff Age Groups Within Major Causes Of Low Vision

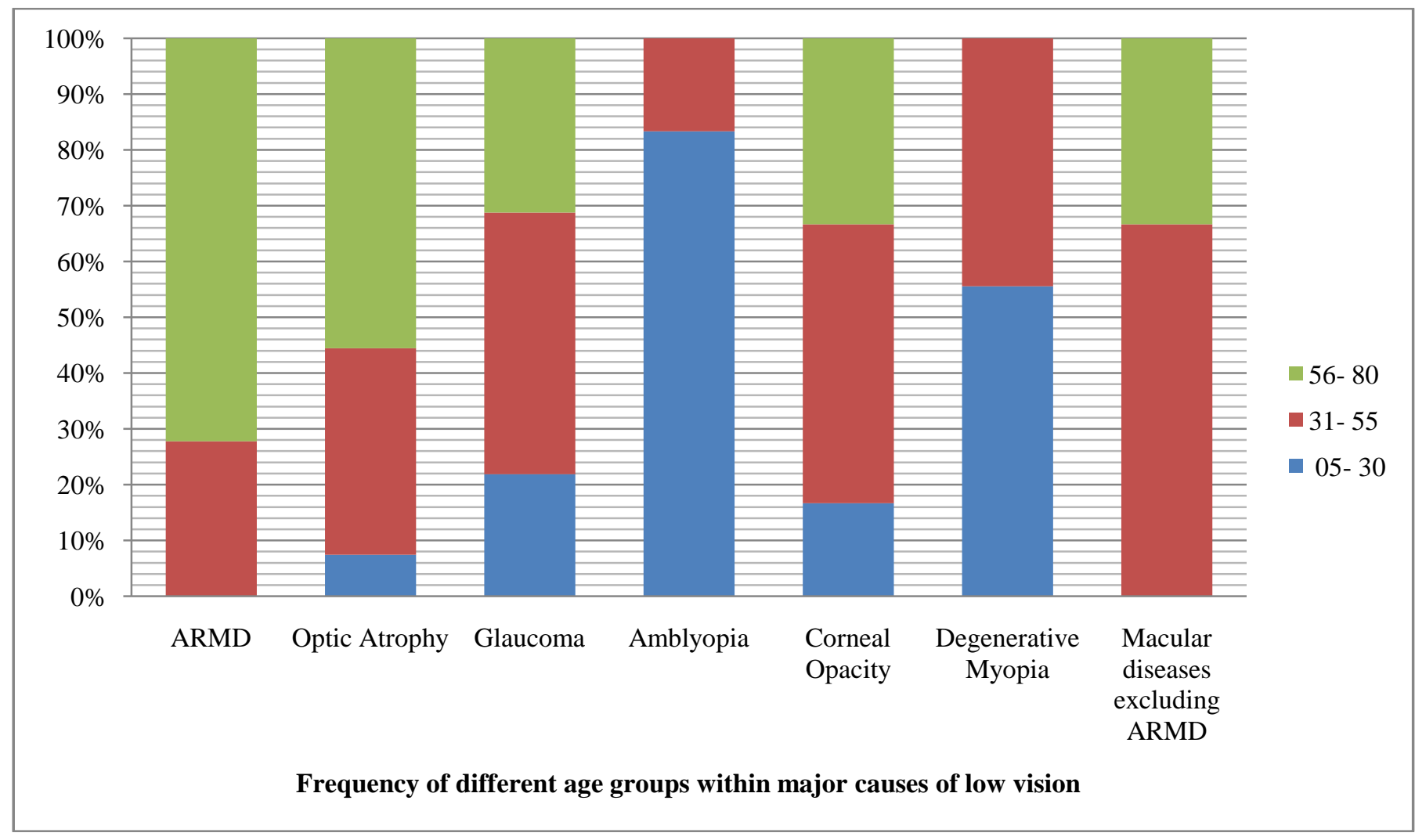

IV. Discussion

This study has presented data from a population of lowvision patients. A major advantage of low visionclinic studies when compared with population surveys,blind school studies or blind register studies is that they provide more reliable and usually detailed ophthalmicinformation about people with low vision [11,12]. However,such information may be rather clinic-specific andbe strongly influenced by the sources of referral as wellas the acceptance and utilisation of low vision servicesby the population served by the particular low visionclinic. In addition, the sample size of such studies isoften limited as was the case in our study. Thus, theyare prone to sampling errors and are limited in their extrapolationto the general population [13]. Notwithstanding,the information obtained from such studiescan be very useful for planning low vision services, activecare and rehabilitation [6].The age distribution of our patients is different fromprevious reports from developed countries but is similarto those from other developing countries.

Although theincidence of low vision has been reported to increasewith age [12], in our study, a significant proportion(35.3\%) of patients were between 26-55 years and majority(41.3\%) were above 56 years of age, while least were in 5-30 years. This depiction of ayounger population is similar to findings from Malaysia[14], Korea [6], Nepal [15], and India [16] in which theproportion of patients aged below 50 years were $74 \%, 69 \%, 58 \%$ and $68 \%$ respectively. In these developingcountries, the proportion of low vision patients aged60 years and above ranged between $16 \%$ and 26\%.On the other hand, in studies from developed countries,Leat and Rumney [17] (United Kingdom) found77\% of their patients to be aged 60 years and above; Elliotet al. [11] (Canada) reported that $66 \%$ of patientswere 70 years or older; while in Australia, Wolffsohnand Cochrane [12] observed that $87 \%$ of patients wereaged 60 years and above. This difference in the patternof the age distribution may be a reflection of the oldergeneral populations in developed countries [11,14] andlow life expectancy in developing countries [16].Despite this fact, thedifference may actually be an indication that the 
olderpopulation in developing countries are less likely toaccess and utilise low vision services than those in developedcountries as a result of lower literacy and a relativelack of interest in reading.The relatively high male to female ratio in our study issimilar to that of other studies conducted in developingcountries as follows: Korea1.8:1 [6], Malaysia- 2.2:1[14], Nepal- 2.3:1 [15], and India- 2.6:1 [16]. It is, however,different from the pattern in developed countrieswhere more females were found to present for lowvision services $[11,12,18]$. This probably demonstratesthe reduced access and utilisation of eye care services byfemales in developing countries $[19,20]$.In our study, however, we found that the proportion of females reduced with age,though this trend was not statistically significant.

Majority of our patients considered their problemswith near and distance vision to be of equal importance.However, elderly patients were more likely to deem nearvision as being their major problem; while children hada tendency to judge distance vision as more important.This observation perhaps portrays the additional effectof presbyopia on low vision in the elderly, although itmay also signify that the elderly have a greater likelihoodof central visual loss from macular disease.Posterior segment disease accounted for the majorityof causes of low vision in this study. This correlates withfindings of most low vision clinic studies $[6,11,12,14-17]$.In our study,the commonestcause was ARMD which is similar to some previous reports who found age related macular degeneration (ARMD) to bethe commonest cause $[11,12,17,18]$.Besides, there are other reports,specifically from developing countries, in which ARMDwas also not the commonest cause $[6,14$ 16]. Possiblereasons for lower prevalence of ARMD in developingcountries may include nutritional factors, less cigarettesmoking, and lower body mass index (BMI) [21]. Furtherresearch is required for a better understanding of therole these factors in developing countries.Glaucoma occupied the third position as a cause oflow vision in our study population (18\%) in contrast tofindings of the Nigerian National Blindness and VisualImpairment Survey in which glaucoma was the mostcommon (26.6\%) cause of functional low vision [3].

Thesmall sample size of our study may account for this difference.It is thus necessary to educate eyecare providers and glaucoma patients about the availableoptions of low vision assessment and low visual aids.Contrary to the previous report by Richard [23] inwhich cataract was the most common cause of low vision,cataract was not present in our study as were not included .The major causes of low vision within the different agegroups as shown in Figure 1 are quite similar to otherreports [12,14]. As expected, congenital and heritable conditionswere more common in children, while age relateddiseases were predominant in the elderly patients.

\section{Conclusion}

It appears that the demographic and clinical characteristicsof low vision patients in our setting are similar tothat of patients in other developing countries, but differentfrom those in developed countries. In addition, elderlypatients and females may be under-utilising lowvision services. We recommend that primary eye carepractitioners including optometrists and general medicalpractitioners bundelkhand region and other developing countriesshould be encouraged to be more mindful about identifyingpatients with low vision, especially females and theelderly and promptly referring such patients for low visionassessment.

Our study would suggest that thecurrent need for low vision care should be directed atproviding support and assistance for adults with age related macular degeneration, corneal opacity ,optic atrophy, glaucomaand children with amblyopia and degenerative myopia.More extensive multicentre research on the characteristicsof low vision patients as well as the determinantsof utilisation of low vision services is necessary to providemore data that would be useful for future planningand delivery of services.

\section{Reference}

[1]. World Health Organisation: The management of low vision of childhood.Bangkok: WHO/PBL/93.27; 1993.

[2]. Gilbert CE, Ellwein LB: Prevalence and causes of functional low vision inschool-age children: results from standardized population surveys inAsia, Africa, and Latin America. Invest Ophthalmol Vis Sci 2008,49(3):877881.

[3]. Entekume G, Patel J, Sivasubramaniam S, Gilbert C, Ezelum C, Murthy GV,Rabiu M: Prevalence, causes and risk factors for functional low vision inNigeria: results from the national survey of blindness and visualimpairment. Invest Ophthalmol Vis Sci 2011, 52(9):6714-6719.

[4]. Shah SP, Minto H, Jadoon MZ, Bourne RR, Dineen B, Gilbert CE, Khan MD:Prevalence and causes of functional low vision and implications forservices: the Pakistan National Blindness and Visual Impairment Survey.Invest Ophthalmol Vis Sci 2008, 49(3):887-893.

[5]. van Dijk K: Providing care for children with low vision. Community EyeHealth 2007, 20(62):24-25.

[6]. Kim JH, Joo KS, Moon NJ: Characteristics of 681 low vision patients inKorea. J Korean Med Sci 2010, 25(8):1217-1221.

[7]. World Health Organisation: Global initiative for the elimination of avoidableblindness. Geneva: WHO/PBL/97.61_Rev.1; 1997. 
[8]. Bach M, Schulze-Bonsel K, Feltgen N, Burau H, Hansen L: Author response:Numerical imputation for low vision states [electronic letter]. InvestOphthalmol Vis Sci 2007.

[9]. Lange C, Feltgen N, Junker B, Schulze-Bonsel K, Bach M: Resolving theclinical acuity categories "hand motion" and "counting fingers" using theFreiburg Visual Acuity Test (FrACT). Graefes Arch Clin Exp Ophthalmol 2009,247(1):137-142.

[10]. Schulze-Bonsel K, Feltgen N, Burau H, Hansen L, Bach M: Visual acuities"hand motion" and "counting fingers" can be quantified with thefreiburg visual acuity test. Invest Ophthalmol Vis Sci 2006, 47(3):1236-1240.

[11]. Elliott DB, Trukolo-Ilic M, Strong JG, Pace R, Plotkin A, Bevers P:Demographic characteristics of the visiondisabled elderly. InvestOphthalmol Vis Sci 1997, 38(12):2566-2575.

[12]. Wolffsohn JS, Cochrane AL: The changing face of the visually impaired:the Kooyong low vision clinic's past, present, and future. Optom Vis Sci1999, 76(11):747-754.

[13]. Elliott DB, Strong G, Trukolo-Ilic M, Pace RJ, Plotkin A, Bevers P: Acomparison of low vision clinic data with low vision survey andblindness registration information. Optom Vis Sci 1998, 75(4):272-278.

[14]. Mohidin N, Yusoff S: Profile of a low vision clinic population. Clin ExpOptom 1998, 81(5):198-202.

[15]. Paudel P, Khadka J, Sharma AK: Profile of a low vision population. IntCongr Ser 2005, 1282:252-256.

[16]. Khan SA: A retrospective study of low-vision cases in an Indian tertiaryeye-care hospital. Indian J Ophthalmol 2000, 48(3):201-207.

[17]. Leat SJ, Rumney NJ: The experience of a university-based low visionclinic. Ophthalmic Physiol Opt 1990, 10(1):8-15.

[18]. Crossland MD, Silver JH: Thirty years in an urban low vision clinic:changes in prescribing habits of low vision practitioners. Optom Vis Sci2005, 82(7):617-622.

[19]. Fletcher AE, Donoghue M, Devavaram J, Thulasiraj RD, Scott S, Abdalla M,Shanmugham AK, Murugan PB: Low uptake of eye services in rural India:a challenge for programs of blindness prevention. Arch Ophthalmol 1999,117(10):1393-1399.

[20]. Snellingen T, Shrestha BR, Gharti MP, Shrestha JK, Upadhyay MP, Pokhrel RP:Socioeconomic barriers to cataract surgery in Nepal: the South Asiancataract management study. Br J Ophthalmol 1998, 82(12):1424-1428.

[21]. Chakravarthy U, Wong TY, Fletcher A, Piault E, Evans C, Zlateva G, Buggage R,Pleil A, Mitchell P: Clinical risk factors for age-related macular degeneration:a systematic review and meta-analysis. BMC Ophthalmol 2010, $10: 31$.

[22]. Abdull MM, Sivasubramaniam S, Murthy GV, Gilbert C, Abubakar T, Ezelum C,Rabiu MM: Causes of blindness and visual impairment in Nigeria: theNigeria national blindness and visual impairment survey. Invest OphthalmolVis Sci 2009, 50(9):4114-4120.

[23]. Richard AI: Causes of blindness and low vision in Bayelsa State, Nigeria: aclinic based study. Nig Q J Hosp Med 2010, 20(3):125-128. 